Canadian

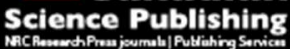

Environmental Reviews Dossiers environnement

\title{
Initiatives to combat mercury use in Artisanal Small Scale Gold mining: A review on issues and challenges
}

\begin{tabular}{|r|l|}
\hline Journal: & Environmental Reviews \\
\hline Manuscript ID & er-2016-0042.R3 \\
\hline Manuscript Type: & Review \\
\hline Date Submitted by the Author: & 14-Oct-2016 \\
\hline Keyword: List of Authors: & $\begin{array}{l}\text { Malehase, Tshia; Tshwane University of Technology, Department of } \\
\text { Environment, Water and Earth Sciences } \\
\text { Okonkwo, Jonathan; Tshwane University of Technology, } \\
\text { Daso, Adegbenro; Tshwane University of Technology, ', Department of } \\
\text { Environmental, Water and Earth Sciences, Faculty of Science }\end{array}$ \\
\hline & \begin{tabular}{l} 
Minamata Convention, artisanal and small scale gold mining, top down- \\
\hline
\end{tabular} \\
\hline
\end{tabular}


1 Initiatives to combat mercury use in Artisanal Small Scale Gold Mining: A review 2 on issues and challenges

3

4 Department of Environmental, Water and Earth Sciences, Tshwane University of Technology, Private Bag X680, 5 175, Nelson Mandela Drive, Arcadia, Pretoria, 0001, South Africa.

Email: OkonkwoOJ@tut.ac.za, Tel: +27 123826245

8 Abstract

9 The Minamata Convention on mercury has received a number of criticisms and challenges that

10 potentially hinder its progress on reducing and controlling mercury use and release by Artisanal

11 Small Scale Gold Mining (ASSGM). The resulting weak environmental control has repercussions

12 for the social and environmental wellbeing of countries that subsist on ASSGM in their territory.

13 Lack of distinguishing and categorizing ASSGM, the absence of a contextual implementation

14 plan, and no defined means of communication are some of the aspects that lead to

15 unsuccessful initiatives, particularly on effectively introducing mercury-free technologies.

16 Moreover, an underestimation of the active mining population implies that the problem is

17 greater than what is perceived. ASSGM is a viable source of poverty alleviation which cannot be

18 ignored and therefore the resulting socio-economic and environmental challenges need to be

19 addressed while optimizing economic benefits. In this paper a compendium of issues and

20 challenges that need to be addressed to reduce and control mercury use and release by ASSGM

21 are discussed. By reviewing the challenges of successful case studies, a comprehensive

22 approach is proposed to enhance the implementation of the Minamata Convention on 23 mercury. 
24 Keywords: Minamata Convention, artisanal and small scale gold mining, top down-bottom up 25 approach, amalgam, mercury

\section{Introduction}

Artisanal and small scale gold mining (ASSGM) is one of the major sources of global mercury

29 pollution and the sector is currently receiving the highest international attention due to the

30 resulting socio-economic and environmental effects caused by this activity. In 2013, it was

31 estimated that approximately $727 \mathrm{t}$ (metric tonnes) of mercury has been released into the

32 atmosphere, which account for approximately 37\% (1960 t) of anthropogenic global mercury

33 emissions (UNEP 2013). Approximately $800 \mathrm{t}$ of mercury is released into the environment

34 annually by ASSGM (Basu et al. 2015). ASSGM contributes significantly to the total global gold

35 production, producing between $380-450$ t of gold per year (Seccatore et al. 2014). Developing

36 countries account for the highest number of ASSGM operations using the lowest available

37 technology. The quality and environmentally friendly nature of ASSGM technology differs from

38 one region to another. For example, in South America, one of the most environmentally

39 friendly techniques is employed (Seccatore et al. 2014). Other strong examples of

40 environmentally friendly ASSGM practices can be found in Central Asia and Central America. In

41 contrast, environmentally unfriendly techniques appear to be most common in Africa

42 (Seccatore et al. 2014). Consequently, sub-Saharan African countries are one of the leading

43 mercury emitting regions in the continent. East Asia appears to be in the same category with

44 the sub-Sahara African Countries (Basu et al. 2015). 
45 ASSGM description has been generalized over numerous artisanal and small scale mining 46 (ASSM) activities even though different minerals and methods are employed, formal or 47 informal, and poses different degrees of social and environmental impacts. A more definite 48 description is needed when dealing with the technical aspects of ASSGM (Seccatore et al. 2014). Recently, Saccatore et al. (2014) estimated that the number of ASSGM to be over 16 million miners who may be directly involved in the mining operations. The estimations on the number

51 of ASSGM population in the literature lack consistency and it is largely underestimated when 52 considering an increasing population and unemployment rates in most developing countries.

53 One of the most basic steps that need to be addressed is an accurate estimate of the global 54 ASSGM population. A number of initiatives to introduce new and improved technology have 55 been undertaken with limited success due to a variety of reasons which mainly includes complex technology and methods, less profit returns, and a lack of training and education. This

57 review argues that it is important to understand area-specific socio-economic and 58 environmental conditions that affect the needs of miners, the importance of training and 59 education, and the necessity to provide financial support in order to effectively introduce a sustainable technology. Because there is growing evidence of socio-economic, environmental

61 and policy challenges that hinder achieving the objectives of reducing, controlling, monitoring,

62 eliminating mercury releases, and emissions by ASSGM, implementing sustainable technology 63 becomes extremely complex (Hilson and McQuilken 2014). Furthermore, suggestions on how 64 countries can prepare and implement the treaty requirements given the region-specific 65 identified challenges, are not clear. Recent studies (Davis 2014; Sippl 2015; Langston et al. 66 2015) have inadequately pinpointed strategies that can assist governments on formalizing 
67 ASSGM, as it is one of the requirements of the Minamata Convention on mercury, whereas the majority of studies have failed to recognize the convention and therefore they do not provide suggestions for cost-effective strategies that would implement the objectives of the convention (Bakia 2014; Hilson and McQuilken 2014; Hilson and Gatsinzi 2014; Veiga et al. 2014; Dondeyne and Ndunguru 2014; Ncube-Phiri et al. 2015; Oramah et al. 2015; Weng et al. 2015). In this review, a collective summary of the aforementioned issues and challenges are presented. Thereafter, a suggestion of communication structure is proposed for countries to be able to successfully formalize and combat mercury use in the ASSGM.

\section{The initiative to combat mercury use in ASSGM}

In view of the mercury poisoning incidences reported throughout the world, the United Nations Environmental Programme (UNEP)'s and Governing Council (GC) initiated global assessment of mercury in 2001 and this has precipitated the Minamata Convention on mercury. The Minamata Convention on mercury has been established as an initiative to reduce global mercury pollution. The treaty has mandated countries "signatories" having ASSGM operations within their territory to take steps to reduce, control, monitor and where feasible, eliminate the use of mercury and mercury compounds, and the emission and release of mercury into the environment. However, the convention has received a lot of criticism pointing at unclear implementation plans, lack of resources in developing countries and the diversity of the factors that exacerbate the ASSGM operation such as poverty, lack of economic alternatives and poor governance. Sippl (2015) has outlined major problems that often lead to the ineffectiveness of 
87 international policies such as the Minamata Convention on mercury which include lack of resources, poor regulations and implementation plans.

89 Since then, UNEP has undertaken to increase the understanding of mercury releasing sources to the environment as it is critical for the development of relevant and cost-effective strategies towards the reduction of this global pollutant. Amongst other requirements, the treaty requires

92 signatories that have ASSGM within their territory to take steps to; develop, submit and

93 implement a national action plan, strategies to prevent mercury pollution, education, research, 94 dissemination of information, and provision of technical and financial support as means of 95 remediating mercury pollution (USEPA 2014). The Minamata Convention on mercury made a 96 bold step to abolish primary mercury mining, with an exception that those mines already 97 operating, may continue for 15 years after the treaty has come into effect. More importantly, 98 mercury mined during the provided period will only be used in the manufacturing of mercury 99 added products. Hence, the direct use of mercury such as in ASSGM should be abolished. It is 100 anticipated that the availability of mercury will decline as a result of enforcement of 101 international policies that phase out mercury use and supply. However, the use of mercury has 102 been regulated over the past decade in some countries such as China, Ghana and Tanzania, 103 with little effect on mercury availability and use (Styles et al. 2010; Viega et al. 2014). The 104 suppliers of "black market" mercury are one of the aspects that have not been entirely 105 researched. This will undoubtedly be a future problem enhancing mercury use in the sector.

\section{The paradox on ASSGM description}


107 The Minamata Convention on mercury defines ASSGM as "gold mining conducted by individual 108 miner or small enterprise with limited capital investment and production". There are different 109 descriptions set by different organizations and commentators, a number of them are outlined 110 by Hilson and McQuilken (2014), and they vary from country to country (Weng et al. 2015).

111 Saccatore et al. (2014) have raised the issue of inconsistency in the description and they 112 proposed a more general definition. ASSGM definition is generalized over a wide range and 113 diversity of artisanal and small scale mining (ASSM) activities. This creates the perception that 114 all ASSM activities employ mercury. For example, in South Africa, there are formalized ASSM 115 using rudimentary techniques that do not involve the use of mercury in gold mining. Moreover, 116 there are mercury-free techniques such as igoli which is widely used in South Africa and in 117 some countries in Africa. This method only involves leaching the gold concentrates with 118 hydrochloric acid and bleach, filter and precipitate gold with sodium metabisulphate (Mintek 119 2011). There are a handful of descriptions of ASSGM, which are defined differently in different 120 countries taking into account the volume of production and output, the amount of capital 121 invested, the size of working force, the size of a claim, the depth of the mine and the level of 122 technology being used (Collins and Lawson 2014). The majority of the descriptions describe 123 ASSGM as mining activity that is characterized by the use of rudimentary processes and 124 technology to extract valuable minerals from primary and secondary ore bodies, lack of long125 term mine planning, rehabilitation measures and monitoring. The description can refer to illegal 126 or legal, formal or informal and it encompasses every activity from individual micro gold miner 127 to medium-scale operations employing thousands of people (Weng et al. 2015). Saldarriaga128 Isaza et al. (2013) found commonalities on the description of ASSGM in different countries 
129 which include low levels of mechanical technology use, labour intensiveness, low 130 environmental awareness, poor education and training, high transience among some miners 131 and lack of financial savings. These definitions are not clear on whether they refer to 132 formalized, illegal or mercury employing miners. For clarity, a fundamental initiative that 133 describes the term is to shift from using such a general term. Rather, ASSM description must 134 enable one to distinguish the difference from Illegal Artisanal Small Scale Mining (IASSM), Illegal 135 Artisanal and Small Scale Gold Mining (IASSGM), Legal Artisanal and Small Scale Gold Mining 136 (LASSGM), Mercury Employing Artisanal and Small Scale Gold Mining (MEASSGM) and Non137 Mercury Employing Artisanal and Small Scale Gold Mining (NMEASSGM). This will provide a 138 more definite description that is needed to clarify the type of ASSM practices on a global 139 perspective especially when dealing with technical matters. For example, ASSM might also refer 140 to the rudimentary extraction of a wide range of ferrous and non-ferrous metals, stones and 141 sand, employing a variety of mining methods and where different numbers of miners are 142 involved.

\section{Different methods of gold extractions used by ASSGM}

144 The operational and processing methods used by ASSGM are well reported, as well as 145 alternative methods to reduce and combat mercury use in the sector (Styles et al. 2010; Davis 146 2014). These methods include milling, disc mills, sluice box, coal-oil agglomeration, centrifuges, 147 magnets, Gemini tables, cyanadation, barox and amalgamation to mention but a few. The 148 majority of these methods are inappropriate, expensive and some take longer to obtain the 149 final product. For example, the sluice box and retorts are inappropriate to be carried out by 
150 miners and it is time consuming, although they are cheaper and environmentally sound when

151 compared to amalgamation.

152 The most popular method used by miners is amalgamation of gold ores or gold concentrates to 153 extract valuable gold from its ores because it is easy to use and miners believe it to be less 154 expensive than other methods (Jønsson et al. 2013; Saldarriaga-Isaza et al. 2013; Davis 2014). 155 During the mining process, mercury can be used at different stages of gold extraction. This 156 includes miners injecting mercury into the pit to collect fine gold; milling, where mercury is 157 placed in the ball mills; and sluicing, where mercury is placed in a sluice box for agglomeration 158 of small particles for easier capturing; panning, where mercury is added to the black sand in a 159 pan, rolled and rubbed through the sand for optimum contact with gold grains to eventually 160 form a gold-mercury amalgam paste. The sand is gradually washed away during the panning 161 process, leaving only the amalgam paste behind. Thereafter, the amalgam paste is heated over 162 a fire or with a blowtorch to drive off mercury as a vapour, leaving behind a yellowish-brown 163 sponge gold. In many cases, the amalgam paste is firstly squeezed (e.g. in a cloth) to eliminate 164 excess liquid mercury that will later be reused (Viega et al. 2014).

Styles et al. (2010) have demonstrated that, despite the simplicity, easy access and favourable 166 use of mercury, the method is inefficient and presents deleterious effects on human health and 167 the environment. Several projects have been initiated to introduce sound technology within the 168 sector, amongst others, the UNIDO Mercury Project have campaigned for the use of safer 169 methods such as retorts in Ghana and Tanzania (Styles et al. 2010; Jønsson et al. 2013). The 170 outcomes of the initiative did not yield great success due to the fact that the method is difficult 
171 to operate, time consuming, cumbersome and often unavailable for purchasing. As a result, the

172 method was inconvenient for miners who are production driven. Secondly, the use of the

173 instrument incurred capital costs to miners who are impoverished and unwilling to invest on a

174 fragile and less productive product. Veiga et al. (2014) suggested that intensive cyanadation of

175 gold concentrates is the most realistic process. In contrast, cyanide is much more poisonous

176 than mercury, when considering unsafe practices that the miners are engaged in. About 909

177 miners were reported dead due to occupational exposure to cyanide in Guyana, Ghana (Veiga

178 et al. 2014). In addition, cyanide is deleterious to the environment and requires to be destroyed

179 by oxidizing it after use. This process cannot be easily adopted by miners. Moreover, the

180 method needs capital investment and production sales (Macdonald et al. 2014). In the direct

181 smelting process, the use of barox has been proven to be more effective compared to the

182 amalgam process, yielding an average recovery rate of $98.3 \%$ compared to $88 \%$ with the

183 amalgam process, at equal time and costs (Amankwah et al. 2010).

184 Greater success can be acquired by introducing a more appropriate technology that enables

185 miners to easily carry out and operate; a technology that is quick, cost-effective, accessible,

186 profitable and environmentally sound. Styles et al. (2010) is of the opinion that for any method

187 to be accepted by the artisanal mining community, it must be simple to use, easily accessible 188 and cost-efficient in a short term. There is a need to understand the socio-economic, legal and 189 environmental state of ASSGM in order to provide an appropriate and effective method that is 190 linked to a proper education, training, financial support and monitoring. Continuous 191 monitoring, training and education after the introduction of a new technology are important 192 because miners are transient. Survey studies (Styles et al. 2010; Veiga et al. 2014) have found 
193 that ASSGM miners are willing to use alternative methods provided it is equivalent or if it 194 outweighs the advantages of mercury use.

\section{The inconsistency in estimating the population of ASSGM}

196

197

198

199

200

201

202

203

204

205

206

207

208

209

210

211

212

213

ASSGM has been wide spread throughout the world for over 2000 years ago (Hilson, 2002b).

Since 2006 until 2015, the estimated number of artisanal and small-scale miners worldwide has been estimated to be between 10-16 million, which in turn supports more than 100 million livelihoods (Drace et al. 2012; Saccatore et al. 2014). There is inconsistency regarding the size of the population of ASSGM. For example, Hilson and Gatsinzi (2014), mentioned that there are 10 million in the sub-Sahara Africa, while elsewhere it is reported that at least 2 million people are directly employed in sub-Saharan Africa (Weng et al. 2015). Recently, Saccatore et al. (2014) estimated that over 16 million people are involved in ASSM globally using only the hypothesis that "ASSGM population is directly proportional to the shift in gold price". There are numerous potential drivers of ASSGM which include population growth, unemployment and poverty, especially in developing countries where these factors have been increasing progressively over the past decades. In Africa for example, population have been increasing in Zimbabwe, Tanzania and Ghana at the rate of $0.62-4.36 \%, 1.83-2.8 \%$ and $2.07-2.19 \%$ from $2006-2014$, respectively (IndexMundi 2015). Consequently, the unemployment rate has been increasing at the rate of $11.7-10.3 \%$ and $12.9-5.2 \%$ percent in Tanzania and Ghana, respectively. In Zimbabwe, the informal sector accounted for over $80-89 \%$ of employment from $2005-2013$ (Saungwame et al. 2014; IndexMundi 2015). Trends of population growth and increases in unemployment rates have been experienced in South American and East Asian countries that 
214 are also known to subsist on ASSGM. For example, population in Venezuela, Brazil and 215 Indonesia have increased by $1.38-1.42 \%, 1.04-0.83 \%$ and $1.41-0.95 \%$ from 2006-2013, 216 respectively. Their unemployment rates have been increasing by $8.9-7.9 \%, 9.6-5.7 \%$ and $12.5-$ 217 6.6\% from 2006-2013, respectively (IndexMundi 2015). The aforementioned calculated 218 estimates on the population of miners are based on data collected from merely 58 countries 219 out of 98 reported gold producing countries in the world (Saccatore et al. 2014). The number of 220 ASSGM population have been underestimated and the problem is greater than what is 221 perceived. Hence, an estimate that reflects the near accurate population of global artisanal and 222 small scale miners is needed that is based on consistent data collected from on-field census.

223 There are many challenges that might result in an inaccurate estimate of the number of 224 ASSGM, and stems from the fact that the majority of miners are transient, seasonal, stay 225 underground for a long period, operate illegally, are unregistered and have no formal 226 appointments.

\section{Socio-economic and environmental challenges caused by ASSGM}

\subsection{Economic challenges}

229 ASSGM is an important economic development tool to alleviate poverty in the developing 230 countries and contributes significantly to national revenues (Teschner 2014). ASSGM activities

231 provide an important source of minerals by fully utilizing deposits that are not favourable to 232 large scale mining (Castro and Sànchez 2003). ASSGM also encourages large scale mines to be 233 more rational and efficient through competition (Shen and Gunson 2006). Poverty and lack of 234 economic alternatives are the main drivers of the population increase in the sector (Weng et al. 
235 2015). The increase in the price of gold in past years also account for the explanation for the

236 recent fashion of ASSGM. The literature has shown that an inexpensive and easy mercury

237 amalgam process is used throughout the world in countries that subsist on ASSGM, and the

238 resulting economic effects are well documented (Styles et al. 2010; Hilson and McQuilken

239 2014). ASSGM is largely practiced in developing countries as it provides an important source of

240 income (employment), particularly in areas where there are few economic alternatives. More

241 than $25 \%$ of the world's gold production is from ASSGM (Drace et al. 2012). Despite the

242 economic benefits brought by ASSGM on families as well as states, the resulting consequences

243 of the activity on the environment and human health cannot be ignored. The negative effects of

244 mercury releases and emissions have been elevated to international concern where initiatives

245 to reduce, control and eliminate the use of mercury are encouraged. Currently, there is

246 increasing attention given to economic conditions around ASSGM, which includes financing an

247 awareness campaign, donating mercury free technology, and funding for education and training

248 facilities. However, this initiative has, so far resulted in limited success because of poor

249 communication networks which has led to improper dissemination of information. Thus,

250 resources result in benefiting few miners and yielding less success on solving the problem of

251 reducing, controlling and eradicating the release, emission and use of mercury by artisanal

252 miners. Avoiding taxes and decommissioning liability costs are one of the major challenges

253 because miners do not want to comply, hence they avoid contact with government officials.

254 The financial support for ASSGM is also augmented by the Minamata Convention on mercury

255 on developing countries to enable the countries to reach the set objectives.

256 6.2. Social challenges of ASSGM 
257 Poverty, lack of socio-economic alternatives and seasonality of agriculture are reported to be 258 the main drivers of people into the ASSGM (Viega et al. 2014; Oramah et al. 2015). A population 259 of more than 16 million people directly depend on ASSGM to sustain their livelihood, and they 260 further extend the support to more than 100 million people (Saccatore et al. 2014). The 261 employment, income and production generated from ASSGM activities come with significant 262 costs to the miners themselves, and to local and global community well-being. The occupational 263 safety of miners is often compromised, the risks associated include underground tunnel failure 264 and fire, machinery accidents, inhalation of mercury vapour and carbon monoxide. Social 265 impacts of ASSGM include human trafficking, forced child labour, prostitution, drug usage, 266 violence and abuse of women (Bashwira et al. 2014; ILO 1999).

267 There are many accidents that occur during ASSGM activities. However, most of the incidents 268 are not reported except in the cases of death, since the activities are illegal (Shen and Gunson 269 2006). The International Labour Organisation estimated that fatal incidents are 6-7 times 270 greater than in the formal mining sector (ILO 1999). Quironga cited by (Shen and Gunson 2006) 271 outlined preliminary strategies to move against social inequality in ASSGM. These strategies 272 include implementing alternative sustainable economic sources with the help of the 273 government, private sector, non-governmental organisations (NGO) as facilitators and partners.

274 The negativity of ASSGM, is that the illegal operations can encroach onto the concessions of the 275 formal mining sector, leading to safety hazards by undermining existing workings while highly 276 grading the deposit. Lack of knowledge and awareness about the effects of mercury on human 277 environment health, and implementing the available alternative mercury free methods are the 278 main social challenges faced by different countries in the world (Styles et al. 2010). 


\subsection{Environmental impacts of ASSGM}

280

281

282

283

284

285

286

287

288

289

290

291

292

293

294

295

296

297 environment (Shen and Gunson 2006).

Mercury is used by ASSGM throughout the world, and the environmental and health effects are largely documented (Styles et al. 2010). The majority of ASSGM depends on mercury to amalgamate gold and separate it from its ores, and they are characterized by improper disposal of resulting waste (Davis 2014). Contamination of surface and groundwater due to released mercury, vapour and dust eroded from MEASSM is a major problem. As a result, significant levels of mercury have been determined in the immediate environment (soil, sediments and aquatic systems) where ASSGM operations exist (Basu et al. 2015; Cobbina et al. 2015). Once mercury is introduced into the environment, it can be eroded by wind and runoff, retained in the environmental by organic matter, plants and organisms or may be emitted into the atmosphere (Lusilao et al. 2013; Xu et al. 2014). In the atmosphere, mercury can be suspended for a long period of up to 10 years and may travel over $1000 \mathrm{~km}$ to be deposited elsewhere. Under aerobic and anaerobic conditions, mercury can be methylated into its most toxic form, methylmercury, which can easily bioacumulate in the food chain to mostly affect the consumers at the top of the food pyramid. Residual waste, burning of mercury and careless handling of mercury are the major contributors to environmental mercury pollution from ASSGM (Castro and Sànchez 2003). ASSGM is a significant source of mercury to the environment, contributing to about $800 \mathrm{t}$ of mercury per year being released into the

\section{Challenges and issues on combating mercury use in ASSGM}


299 Hilson and Gatsinzi (2014) have outlined the efforts made over the past decades to formalize the ASSGM sector, highlighting the paradox between the government regulatory frameworks, 301 socio-economic development and environmental sustainability. A number of initiatives have 302 been put in place across the world aimed at reducing, controlling and phasing out mercury use in ASSGM, particularly its releases into the environment. Governments have set regulations that seek to address the social, environmental and economic aspects of the sector. However, 305 the compliance of artisanal miners is generally low as a result of lack of education, financial and technological support, as well as weak governance (Bugnosen, 2000; Kambani 2003; Shen and

307 Gunson 2006). For example, Ghana and Tanzania are one of the developing countries that have 308 a long history of legalized ASSGM, and lots of interests have been generated by the governments in this sector because of its socio-economic benefits. However, due to a lack of necessary education, technical and financial support that encourages sustainable mining, most operations are poorly managed environmentally (Crispin 2003; Jønsson et al. 2013). In Nigeria, an attempt to develop ASSGM was made by the World Bank, with a financial injection of about US\$10 million, however the investment yielded disappointing returns (Oramah et al. 2015).

314 A more positive example is the initiatives that have been undertaken by the Department of 315 Mining in Papua New Guinea and Chile which incorporates a proactive source of educational activities and information gathering for ASSGM. This initiative has led to improvements in the

317 sector and the government has been able to develop a comprehensive development plan for ASSGM (Crispin 2003; Castro and Sànchez 2003). The Papua New Guinea initiative has resulted in gaining support from private sectors and NGO's from local and international communities, attempting to improve the socio-economic and environmental conditions of the country which 
321 are vital for poverty alleviation and state development. A similar intervention was undertaken

322 by the government of China. Despite ASSGM being illegal in China, the Chinese government is

323 intimately involved and encourages sustainable artisanal mining (Shen and Gunson 2006). The

324 government of Mozambique initiated a scheme that promotes technologies and encourages

325 ASSM to be established as a business by creating a miners association and this has proved to be

326 a success (Dondeyne and Ndunguru 2014). In South Africa, Mintek Small-scale and beneficiation

327 division has established a training school that provides ASSGM with an outcome-based

328 theoretical and practical training, that aspire and assists with legal compliance, and have

329 introduced "igoli technique" as an efficient method to be used by ASSGM for extracting gold

330 from its ores (Mintek 2011).

331 Despite many initiatives to educate, train, reduce, control, monitor and eliminate the use of

332 mercury in ASSGM communities, success has been limited (Drace et al. 2012). The resulting

333 limited success is due to the number of factors that are centred on; (1) lack of a communication

334 network, (2) failure to disseminate relevant information and technology and, (3) lack of

335 monitoring, training and education. Several studies focused on seeking to improve the overall

336 situation of ASSGM (Hilson 2002a; Shen and Gunson 2006; Sippl 2015). They argue that the

337 international community has the potential to improve the sustainability in the ASSGM sector

338 by; (1) legalizing ASSGM and implementing sector-specific legislation; (2) contributing to

339 community development and providing increased community support; (3) providing training

340 and educational assistance; (4) playing and expanding the role in the dissemination and transfer

341 of skills and technology; (5) developing and implementing appropriate licensing procedures for

342 ASSGM; (6) improving coordination among public entities responsible for the control of the 
343 ASSGM sector, and (7) carrying out research and circulating environmentally sound mining 344 technology. More importantly, all inclusive (public, private, NGO's, community) mining 345 structures can provide the solutions to the implementation gaps identified (Sippl 2015; 346 Langston 2015). Implementing these initiatives could facilitate the reduction of mercury 347 pollution on the site. Therefore, introducing alternative technologies aimed at reducing 348 mercury usage and release of mercury requires a far better implementation plan than policy 349 enforcement. This could be enhanced by developing an all-inclusive communication network 350 which takes into account all factors and challenges that are prone in the ASSGM sector.

352 In African countries such as Ghana, Mali, Nigeria and Tanzania, the legal ASSGM is recognized 353 and encouraged by the governments; however, a mining permit/lease or pass must be obtained 354 to be recognized. The formalization is aimed at controlling the emission and release of mercury 355 from ASSGM activities (Uka 2011; Veiga et al. 2014; Oramah et al. 2015). Furthermore, the 356 initiative provides the opportunity to tax royalties and keep a register of miners. However, such 357 initiatives are not acceptable to miners. This initiative has resulted in a number of failures, 358 because artisanal miners do not want to pay tax that will not lead to immediate profits returns, 359 go through bureaucratic protocols of obtaining mining rights, comply with the environmental 360 laws and pay decommissioning rehabilitation costs.

361 Other reasons include, but are not limited to, lack of information, education and support on 362 how to obtain the mining rights and how to improve on gold extraction methods, protect the 363 environment and handle mercury safely. The absence of a government authority in remote 
364 ASSGM areas to monitor compliance and the diversity of miners from those who are 365 mechanized to those who pan sand on river banks, makes it difficult for government officials to 366 fully monitor the operations. A properly formalized ASSGM is an intricate process for both 367 miners and the government if appropriate strategies are not developed and implemented 368 (Veiga et al. 2014). Several governments have struggled to formalize ASSGM (Hilson and 369 McQuilken 2014; Oramah et al. 2015; Davis 2014). For example, Tanzania mining Act of 2010, 370 mandate miners to use retorts while heating gold-amalgam. Hence Veiga et al. (2014) argued 371 that the regulations are not always a solution for experienced mercury usage, release and 372 emission problems. Several studies (Oramah et al. 2015; Weng et al. 2015; Sippl 2015) have 373 outlined commonalities that result in successful ASSGM mining. These successes have been 374 possible because of involvement of the government, NGOs, private sector and the communities 375 where the ASSGM activity operates. Figure 1 illustrates a proposed communication hierarchy 376 structure (top down-bottom up approach) that can be effectively applied to promote 377 sustainable ASSGM. It has been developed from a number of successful and unsuccessful 378 initiatives on combating mercury use by ASSGM, particularly from the work of Sippl (2015). The 379 proposed structure places emphasis on communication being facilitated in a harmonized 380 manner amongst the interested and affected parties. A top down-bottom up approach is a 381 means of communication that is integral for effectively formalizing, reducing and controlling the 382 use of mercury, release and emission by ASSGM. There is a growing consensus that the 383 community must be included in the management of mining activities in order to catalyze broad384 based economic development whilst simultaneously achieving maximum social and economic 385 benefits (Langston et al. 2015). If the communication is between the government and ASSGM, 
386 miners may by-pass the rules, however, if the miners, community leaders and private sectors

387 are involved together equally with the government by-passing of the rules by miners can be 388 avoided. The government and private sectors should provide aid and support to the 389 communities where mining is taking place, assist miners with the process of attaining the 390 mining rights, training, education and appropriate technology. The private sector can also buy 391 gold from the miners on behalf of the government and could be tasked to keep register and 392 provide technical assistance to artisanal miners (Dondeyne and Ndinguru 2014). Langston et al. 393 (2015) is of the opinion that an approach incorporating social, political, economic and 394 environmental issues in a decentralized, but geographically focused management arrangement 395 will help to address the sense of illegality that runs through the ASSGM sector. The top down396 bottom up approach will enhance the understanding of demographics, ethical background, the 397 community interest and the level of education that enhance an appropriate technology, 398 management measures and monitoring the sector to achieve sustainable ASSGM.

399 Kambani (2003) suggested that, the challenge on institutions that are responsible for managing 400 ASSGM efficiently are unable to carry out regulatory and monitoring mandates due to 401 inadequate resources. The regulatory challenge faced by poverty enshrined ASSGM is the 402 bureaucracy and embedded costs to carry out environmental impact assessment and 403 management plans before a mining lease or exploration right is granted. These bureaucratic 404 and costly processes are difficult to artisanal miners when considering their background. Many 405 developing countries have introduced laws and regulations for their perspective ASSGM sector, 406 but these have not necessarily helped on improving the social and environmental problems 407 associated with ASSGM (Bugnosn 2000). In view of the requirements of the Minamata 
408 Convention on mercury, if clear and proper communication guidelines are not put in place, the 409 future of the Minamata Convention on mercury looks grim. Sippl (2015) argues that many 410 signatories of the treaty have ASSGM regulations in place but lack the will and ability to enforce 411 them. Because enforcing regulations on ASSGM alone have proven ineffective in curbing 412 mercury pollution, an effective introduction of new technology must be accompanied by a 413 comprehensive approach (Macdonald et al. 2014). 


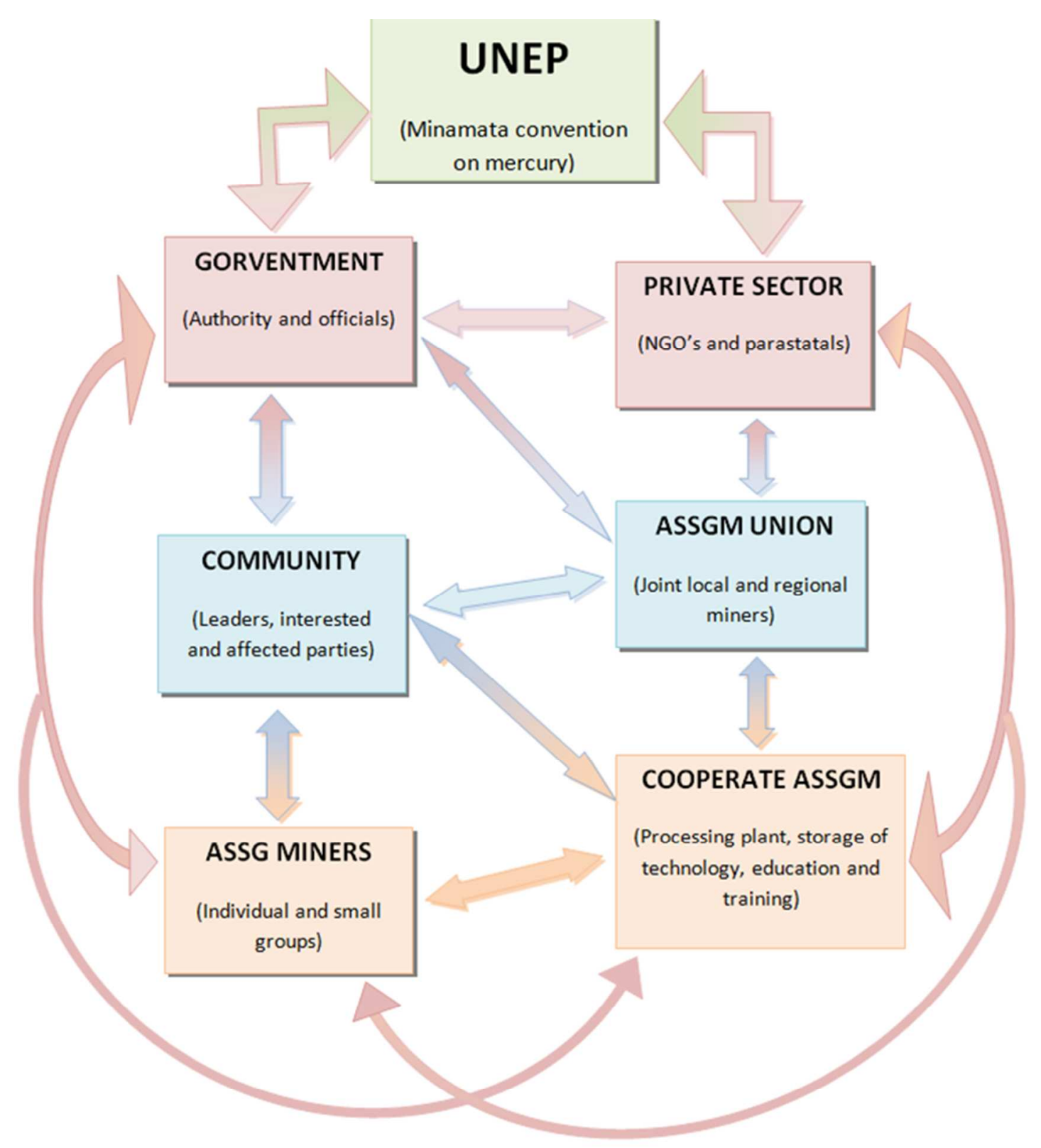

414

415 Figure 1. A proposed communication hierarchy to enhance the implementation of the 416 Minamata Convention on mercury. 
420 Despite the negative challenges and issues associated with ASSGM, the activity has proven to

421 be a viable economic source that can potentially support rural development and profits to the

422 government (Oramah et al. 2015). However, the states rarely invest on ASSGM development

423 (Shen and Gunson 2006). Several studies argue that the contribution of ASSGM may outweigh

424 its negative impacts, especially if the government put forth greater effort to regulate, guide and 425 encourage the development of the sector and create a sound environment for the operations.

426 Shen and Gunson (2006) are of the opinion that ASSGM is a corner-stone of future economic

427 development, particularly for disadvantaged communities. This is more relevant in the current

428 increase in unemployment rate in countries such as South Africa, where the unemployment

429 rate is currently at 25.5\%. An appropriate system of laws and regulations, and suitable

430 institutional structures for the administration of ASSGM are important requirements for the

431 effective management of the sector. Government, regional and international bodies must play

432 an expanded role in disseminating important information, technology and economic support.

433 The question that remains unanswered is the kind and structures of legislations that will

434 efficiently regulate ASSGM.

435 The present review has provided a reliable and self-proven communication structure that can

436 enhance the implementation of the requirements of Minamata Convention on mercury. It is 437 certain that ASSGM will continue to play an important role in the development of any country. 438 Based on the international literature, ASSGM has long existed and cannot be expected to 439 effectively regulate itself and mitigate its own negative impacts. Regulating the sector does not 
440 mean destroying it, therefore, a sound and sustainable ASSGM need to be enhanced (Shen and 441 Gunson 2006). However, if properly managed, the sector can bring tangible, but short term 442 benefits to the communities involved and this can overweigh the health cost incurred, 443 environmental pollution, waste of natural resources and market distortions.

444 Overall, the social and environmental issue of ASSGM tend to outweigh the economic benefits.

445 Lack of knowledge and awareness about the effects of mercury on human health, 446 environmental and alternative mercury-free methods are the main challenges faced by the 447 majority of countries that subsist on ASSM within their territory. This is exacerbated by 448 shortage of financial support, alternative economic activities, and high unemployment rates. In 449 contrast, several funded initiatives have been undertaken to address the aforementioned 450 challenges in ASSGM, and the majority were unsuccessful. However, the benefits support more 451 than 100 million people as a means of poverty alleviation.

452 The Minamata Convention on mercury remains an important tool for protecting human health 453 and the environment from anthropogenic mercury pollution. Continuous attempts must be 454 made to address negative impacts while optimizing the benefits. The top down-bottom up 455 approach is an instrumental approach for effective management of ASSGM and for achieving 456 the objectives of the Minamata Convention on mercury in a timely manner. The success 457 depends on the way technology, training, education and financial support is being introduced. 458 This approach will certainly drive the initiatives on combating mercury use and changing the 459 perception on ASSGM. 
The financial assistance of Deutscher Akademischer Austausch Dienst - National Research

Foundation (DAAD-NRF) towards this research is hereby acknowledged, opinions expressed and conclusions arrived at, are those of the author's and not necessarily to be attributed to the

DAAD-NRF.

\section{References}

Amankwah, R.K., Styles, M.T., Narty, R.S., Al-Hassan, S. 2010. The application of direct smelting of gold concentrates as an alternative to mercury amalgamation in small-scale gold mining operations in Ghana. International Journal Environment and Pollution. 41. 3-4.

Bakia, M. 2014. East Cameroons artisanal and small-scale mining bonanza: How long will it last?. Futures. 62. 40-50.

Bashwing, M.R., Cuvelier, J., Hilhorst, D., Haar van der G. 2014. Not only a mans world: Woman's involvement in artisanal mining in eastern DRC. Resource policy. 40. 109-116.

Basu, N. Clarke, E., Green, A., Calys-Tagoe, B., Chan, L., Dzodzomenyo, M., Fobil, J., Long, R.N., Neitzel, R.L., Obiri, S., Odei, E., Ovadje, Quansah, R., Rajaee, M., Wilson, L.W. 2015. Integrated assessment of artisanal and small-scale gold mining in Ghana- Part 1: Human Health Review. International Journal of Environmental Research and Public Health. 12. 5143-5176.

Bugnosen, E., Twigg, J., Scott, A. 2000. Small-scale legislations and regulatory framework. Industry and Environment. 23. 50-53 [special issues].

Cobbina, S.J., Duwiejuah, A.B., Quansah, R., Obiri, S., Bakobie, N. 2015. Comparative assessment of heavy metals in drinking water sources in two small-scale mining in Northern Ghana. International Journal of Environmental Research and Public Health. 12. 10620-10634.

Castro, S.H., Sànchez, M. 2003. Environmental viewpoint on small-scale copper, gold and silver mining in Chile. Journal of cleaner production. 11. 207-213.

Collins, N., Lawson, L. 2014. Investigating approaches to working with artisanal and small-scale miners; A compendium of strategies and reports from the field. IM4DC action Research report.

Crispin, G. 2003. Environmental management in small scale mining in PNG. Journal of cleaner production. 1. 175-183.

Davis, G.R. 2014. A toxic free future: Is there a role for alternative to mercury in small-scale 
gold mining. Futures. 62. 113-119.

Dondeyne, S. Ndunguru, E. 2014. Artisanal gold mining and rural development policies in Mozambique: Perspectives for the future. Futures. 62. 120-127.

Drace, K., Kiefer, A.M., Viega, M.M., Williams, M.K., Ascari, B., Knapper, K.A., Logan, K.M., Breslin, V.M., Skidmore, A., Bolt, D.A., Grant, G., Reidy, L., Cizdzeil, J.V. 2012.Mercury-free, small-scale artisanal gold mining in Mozambique: utilization of magnets to isolate gold at clean tech mine. Journal of Cleaner Production. 32. 88-95.

Hilson, G. 2002a. Small scale mining and its socio-economic impacts in developing countries. Natural Resource Forum. 26. 3-13.

Hilson, G. 2002b. The future of small-scale mining; environmental and socio-economic perspectives: Futures. 34. 863-872.

Hilson, G., McQuilken, J. 2014. Four decades of support for artisanal and small-scale mining in sub-Sharan Africa; A critical review. The extractive industry and society. 1. 104-118.

Hilson, G., Gatsinzi, A. 2014. A rocky road ahead? Critical reflection on the futures of smallScale mining in Sub-saharan Africa. Futures. 62. 1-9.

IndexMundi, 2015. Historical data graphs per year. http://www.indexmundi.com $/ \mathrm{g} / \mathrm{g} \cdot \mathrm{aspx}$ ? $\mathrm{v}=24 \& \mathrm{c}=\mathrm{sf} \& \mathrm{l}=\mathrm{en}$

International Labour Organisation (ILO), 1999. Social and labour issues in small-scale mines. Report for discussion at the Tripartite Meeting on the Social and Labour Issues in Smallscale Mines. International Labour Organisation, Sectoral Activities Programme, International Labour Office, Geneva.

Jønsson, J.B. Charles, E., Kalvig, P. 2013. Toxic mercury versus appropriate technology: Artisanal gold miners' retort aversion. Research policy. 38. 60-67.

Kambani, S.M, 2003. Small-scale mining and cleaner production issues in Zambia. Journal of Cleaner Production. 11. 141-146.

Langston, J.D., Lubis, M.I., Sayer, J.A., Margules, C., Boedhihartono, A.K., Dirks, P.H.G. 2015. Comparative development benefits from small and large scale mines in North Sulawesi, Indonesia. The Extractive Industry and Society. xxx. xxx-xxx.

Lusilao, M.J.G, Cukrowska, E.M., Tessier, E., Amouroux, D., Weirersbye, I. 2013. The impact of post gold mining on mercury pollution in the West Rand region, Gauteng, South African Journal of Geochemical Exploration. 134. 111-119.

Macdonald, F.K.F., Lund, M., McCullough, C. 2014. Regulation of artisanal small scale gold mining (ASGM) in Ghana and Indonesia as currently implemented fails to adequately protect aquatic ecosystems. An interdisciplinary response to mine water challenges. ISBN 978-7-5646-2437-8.

Mintek, 2011. Mercury-free extraction process. Small Scale Mining and Beneficiation. http://www.mintek.co.za/wp-content/uploads/2012/10/Igoli-Brochure.pdf

Ncube-Phiri, S., Ncube, A., Mucherena, B., Ncube, M. 2015. Artisanal small-scale mining: Potential ecological disaster in Mzingwane district, Zimbabwe, Jamba. Journal of Disaster Risk studies. 7. 1-11. 
Oramah, I.T., Richards, J.P., Summers, R., Garvin, T., MacGee, T. 2015. Artisanal and small scale mining in Nigeria: Experiences from Nigeria, Nasarawa and Plateau states. The Extractive Industries and Society. [in press]

Saungwame, T., Matsvai, S., Sakuhuni, R.C. 2014. Econometric analysis of unemployment, output and growth of informal sector in Zimbabwe (1985-2013). International Journal of Economics and Research. v5i2, 1-9.

Seccatore, J., Veiga, M., Origliasso, C., Morin, T., Tomi De G. 2014. An estimate of the artisanal production of gold in the world. Science of Total Environment. 496. 662-667.

Saldarriaga-Isaza, A., Villegas-Palacio, Arango, S. 2013. The public good dilemma of a nonrenewable common resource: A look at the facts of artisanal gold mining. Resource policy. 38. 224-232.

Shen, L., Gunson, A.J. 2006.The role of artisanal and small-scale mining in China's economy. Journal of Cleaner Production. 14. 427-435.

Sippl, K. 2015. Private and civil society; governors of mercury pollution from artisanal and small-scale gold mining; A network analytic approach. The extractive Industries and Society. 2. 198-208.

Styles, M.T., Amankwah, R.K., Nartey, R.S. 2010. The identification and testing of a method for mercury-free gold processing for artisanal and small-scale gold miners in Ghana. International Journal of Environmental Pollution. 290-303.

Teschner, B.A. 2014. "Orpaillage pays for everything”: How artisanal mining supported rural institutions following Mili's coup d'état. Futures. 62. 140-150.

Uka, C. 2011. Formalization and legalization of artisanal and small-scale mining in Nigeria. A presentation at the regional multi-stakeholders workshop: Anglophone West Africa Sub-Regional Action planning on mercury use in artisanal and small scale gold mining, organised by the United Nations Environmental Programme.

UNEP 2013. Global mercury assessment; Sources, Emissions, Releases and Environmental Transport. UNEP Chemical Branch, Geneva, Switzerland.

USEPA. 2014. Minamata convention on mercury. Available from: www.epa.gov/international-cooperation/minamata-convention-mercury\#convention

Veiga, M.M., Angeloci-Santos, G., Meech, J.A. 2014. Review of barriers to reduce mercury use in artisanal gold mining. The extractive industries and Society. 1. 351-361.

Weng, L., Endamana, D., Boedhihartone, A.K. Lavang, P., Margus, C.R., Sayer, J.A. 2015. Asian investment at artisanal and small-scale mines in rural Cameroon. The Extractive Industries and Society. 2. 64-72.

Xu, J., Kreja .B. D., Biester, H., Lagerkvist, A., Kumpiene, J. 2014. Influence of particle size distribution, organic carbon, $\mathrm{pH}$, and chlorides on washing of mercury contaminated soil. Chemosphere. 109. 99-105. 